\title{
o que "andam sussurrando em versos e trovas"? A militância popular contra D. Miguel e as relações entre Brasil e Portugal. Torres Vedras, 1828-1834 ${ }^{1}$ What "Have They Been Whispering in Verses"? Popular Activism against D. Miguel and Relations Between Brazil and Portugal. Torres Vedras, 1828-1834
}

Andréa Lisly Gonçalves*

\section{Resumo}

O principal objetivo deste artigo é apontar a continuidade dos vínculos entre Portugal e Brasil durante o período subsequente à independência da ex-colônia portuguesa na América, incluindo os anos do reinado de D. Miguel (1828-1834) até a vitória das forças liberais comandadas por D. Pedro IV em solo lusitano. A proposta é realçar o papel das pessoas comuns, portugueses em sua totalidade que, a partir das perseguições sofridas pelas forças repressivas de D. Miguel, reforçaram as ligações entre o Reino e o Império do Brasil. Quanto às fontes, o ponto de partida é a devassa aberta em Torres Vedras, Portugal, para apurar os crimes de sedição contra o Infante, aclamado rei pelas cortes tradicionais do Reino. Em seguida, se dará destaque aos processos movidos contra os que foram acusados de defender a legitimidade de D. Pedro I ao trono português e a vigência da carta constitucional por ele outorgada a Portugal, no ano de 1826.

Palavras-chave: D. Miguel; Constituição de 1826; D. Pedro I.

\section{Abstract}

The aim of this article is to point out the links between the history of Portugal and Brazil, in the aftermath of Brazil's independency, from the reign of $\mathrm{D}$. Miguel (1828-1834) to D. Pedro IV's victory in civil war. One of the purposes is to emphasize the role played by common Portuguese people who were persecuted by the forces of D. Miguel. Regarding the sources, the starting point is the inquiry which took place in Torres Vedras, Portugal, to punish crimes of sedition against the king who had been acclaimed by the traditional courts. Afterwards the focus will be on the lawsuits filed against ordinary people who were charged defending the legitimate right of D. Pedro I to the Portuguese throne and the legitimacy of the constitution of 1826 , that was signed by the king of Brazil and granted Portugal.

Keywords: D. Miguel; Constitution of 1826; D. Pedro I.

\footnotetext{
* Universidade Federal de Ouro Preto (UFOP), Mariana, MG, Brasil. alisly@terra.com.br $<$ https://orcid. org/0000-0002-6586-2459>
} 
A vida do português Diogo Carlos Temudo de Mendonça parece ter sido das mais aventurosas. Filho de Gaspar Félix de Mendonça e de D. Maria Gertrudes Bárbara da França e Horta, seu avô paterno, de quem herdara o nome, tinha sido Porteiro da Câmara dos infantes D. Gaspar, D. José e D. Antônio, os meninos da Palhavã. ${ }^{2}$ Nascido no ano de 1794, em Torres Vedras, fora degredado para Angola em 1818, aos 24 anos, pelo crime de deserção (ANTT, Maço 14, n. 4).

Cumprida a pena, embarcou no brigue Lucrécia, de volta a Portugal. Há registros de que o Lucrécia partira do Reino em direção a Angola, em 1826, tendo o seu dono solicitado passaporte para a realização de tráfico negreiro (Rodrigues, 2017, p. 1-18). O passaporte era uma exigência dos tratados assinados entre Portugal e as potências europeias para colocar fim ao tráfico de cativos. Os mesmos tratados, porém, tinham tornado ilegal o comércio de escravos, feito por portugueses, para fora do Império luso, o que incluía o Brasil, pelo menos desde o reconhecimento de sua independência por Portugal, em 1825. O proprietário do brigue era Manuel Ribeiro da Silva, um negociante lisboeta que, nascido em 1767, "entre os 40 e os 60 anos de idade, fez fortuna no comércio ultramarino e estabeleceu relações sólidas com comerciantes de Lisboa e dos portos do norte do Brasil" (Rodrigues, 2017, p. 9).

Se era do interesse do dono do Lucrécia esconder que os cativos foram destinados ao Brasil, o fato de o navio ter naufragado na costa do Maranhão, no mês de novembro de 1827, não deve ter facilitado a tarefa. Seja como for, são e salvo, Temudo apressou-se em retornar a Lisboa, partindo do Maranhão na galera São Nicolau. A viagem, porém, não durou muito. Depois de dois dias ao mar, a embarcação foi assaltada por piratas. Temudo, então, foi parar de novo na costa maranhense, mais precisamente "na cidade de Cachoeira", demorando-se naquele lugar até conseguir embarcar no brigue Bizarria, uma antiga embarcação portuguesa de propulsão a vela, chegando, finalmente, a Lisboa.

Transcorridos quase três anos de seu retorno, Temudo foi acusado, pelas forças policiais de Torres Vedras, de "dar vivas sediciosos" e de apresentar péssima conduta moral e política. O processo de Temudo que localizei no Arquivo Nacional da Torre do Tombo não contém depoimentos de testemunhas ou a sua defesa. Dessa forma, não há como detalhar as razões que o levaram à condenação, em 10 de julho de 1832, a mais cinco anos de degredo, agora para a Guiné Bissau. Não sabemos, também, se a sentença foi cumprida.

As passagens da história da vida de Diogo Temudo, que as fontes permitem reconstituir de forma breve, inserem-se no período que vai da elevação do Brasil a Reino Unido a Portugal e Algarves até os anos subsequentes à inde- 
pendência do país e o reconhecimento da separação, pela ex-metrópole, em 1825. Elas apontam a inevitável unidade desse mesmo império, que persiste por muitos anos não apenas no que diz respeito às províncias setentrionais, ${ }^{3}$ em cuja costa foi dar Temudo, mas a todo o território brasileiro.

A dependência da ex-colônia portuguesa em relação ao tráfico internacional de escravos, sobretudo os da costa angolana, só fez recrudescer nas primeiras décadas do oitocentos, a ponto de uma parte da Junta Governativa que se instalou em Luanda após a Revolução do Porto e de mais de um dos deputados eleitos por Angola às Cortes de Lisboa serem favoráveis à junção de Angola ao Brasil (Mourão, 1999), o que aumentou os esforços de Portugal no sentido de diminuir a influência da ex-colônia na América junto às suas possessões naquele continente, encontrando resistência, porém, da parte de vários grupos situados na África e no Oriente, à manutenção dos vínculos no interior do império. ${ }^{4}$

Contrariando os autores que tenderam a destacar a quase exclusividade do comércio negreiro entre as praças brasileiras e a costa angolana, as conclusões da historiografia recente - de que Portugal também controlava parte do tráfico de africanos escravizados - reforçam a perspectiva, aqui adotada, de que os laços, inclusive com a ex-metrópole, continuavam firmes nas décadas de 1820 e 1830.

Por outro lado, os projetos de reaproximação entre Portugal e Brasil vão ganhar força renovada após a morte de D. João VI e se estender até pelo menos 1834, com o fim da guerra civil portuguesa (Gonçalves, 2012). São as constatações desse vínculo, que as histórias de Temudo parecem simbolizar, que me levam a incluir os nascidos em Portugal entre os personagens que compõem o universo da minha investigação sobre os presos políticos do reinado de D. Miguel (1828-1834).

Primeiramente, minhas pesquisas centraram-se nas trajetórias dos brasileiros que, em Portugal, foram acusados de fazer oposição a D. Miguel. A constatação da participação de brasileiros na militância antimiguelista na antiga metrópole não me surpreendeu, apesar de se tratar de um tema original, principalmente no âmbito da historiografia nacional. Afinal, tratava-se da crise do império luso-brasileiro e dos seus desdobramentos. Em seguida, ocupei-me dos estrangeiros processados sob a acusação de defender o liberalismo e de conspirar contra o rei aclamado pelas cortes tradicionais do Reino, em julho de 1828. Foi na busca de explicação para o envolvimento dessas pessoas de diferentes nacionalidades, ou protonacionalidades - uma vez que o processo de formação dos Estados Nacionais contemporâneos, nas primeira décadas do 
século XIX, ainda se encontrava no seu início (Anderson, 2008; Cassino, 2015) - que tomei conhecimento da intensa movimentação de liberais na Europa do sul. Ficou evidente que muitos liberais no exílio acalentavam o projeto de unidade de Portugal e Espanha, sob a Coroa do Primeiro Imperador do Brasil, bem antes da sua abdicação, a 7 de abril de 1831. Para tanto, parece ter sido decisiva a outorga da Carta constitucional do Brasil a Portugal, em 1826, por D. Pedro, devidamente adaptada ao Reino, num contexto marcado pela ampla mobilização liberal na Europa do sul. Tanto as lideranças liberais moderadas quanto as exaltadas chegaram a propor D. Pedro I como rei de Espanha, sob a justificativa de que, por ser filho de D. Carlota Joaquina, irmã de Fernando VII, estaria respeitada a sucessão dinástica (Suanzes-Carpegna, 2010).

O Imperador do Brasil começou a receber comunicados nesse sentido desde 1826. A proposta perdurou até o ano de 1833, quando a morte de Fernando VII forçou o reposicionamento dos liberais em apoio a Dona Isabel contra a ofensiva absolutista representada pelo Carlismo (Brancato, 2014). Que a ideia de que D. Pedro poderia ocupar o trono espanhol já andava nas cabeças e nas bocas da gente comum ${ }^{5}$ nos dá notícia a afirmação atribuída ao escrivão dos exercícios dos julgados, ${ }^{6}$ José Manuel dos Reis, morador em Torres Vedras, segundo a qual "D. Pedro estava no Rio Tejo, e que ia governar a Espanha. D. Maria da Glória vinha governar Portugal e que El Rei D. Fernando já tinha fugido..." (ANTT, Maço 37, n. 10).

A subida de D. Miguel ao trono, em julho de 1828, se não conteve toda essa mobilização, inaugurou um tempo de perseguições, de exílios no estrangeiro, na Europa e nas Américas; forçou à clandestinidade aqueles acusados de se posicionar a favor do liberalismo, efetuou prisões, instaurou processos políticos. No concelho de Torres Vedras, próximo a Lisboa, foi aberta uma devassa para apurar os crimes políticos cometidos contra o rei "absoluto". Cheguei à referida devassa ao pesquisar o caso de um brasileiro, o cirurgião prático José Faustino Gomes, natural de Pernambuco, que em 1831 foi preso por milicianos miguelistas, acusado de irreligioso, liberal, partidário de D. Pedro I e de "ter feito a revolução no Brasil" (Gonçalves, 2019).

A maioria dos envolvidos implicados na devassa, porém, é constituída de portugueses, entre os quais Diogo Carlos Temudo de Mendonça. As informações disponíveis mostram que suas histórias se relacionavam à do Brasil por, pelo menos, três pontos. O primeiro, e mais recorrente, o apoio a D. Pedro como o legítimo rei de Portugal; o segundo, correlato ao anterior, a defesa da Constituição outorgada pelo mesmo imperador a Portugal, em 1826. O terceiro pelo fato de que pelo menos dois desses personagens, nascidos no Reino e 
então moradores em Torres Vedras, como se verá, mantinham laços com o Brasil, que se afigurava como possível destino para os que buscavam fugir à perseguição desencadeada por D. Miguel a seus opositores. Mais uma vez, portanto, ressaltaram-se os vínculos entre a história do Brasil e a de Portugal, o que me levou a incorporar parte considerável da militância portuguesa em minhas pesquisas.

Após apresentar algumas considerações sobre o local que foi o palco dessas movimentações políticas - Torres Vedras -, abordo, neste artigo, aspectos da história de vida de sujeitos específicos, acusados de se voltar contra aquele que se aclamara rei em 1828. As fontes seguem sendo os processos políticos do reinado de D. Miguel, depositados no Fundo dos feitos findos, na Torre do Tombo. ${ }^{7}$

A existência de correspondências, de registros poéticos de próprio punho e de folhas periódicas juntados aos autos permite que se lance luz sobre os envolvidos para além das informações produzidas por escrivães, testemunhas e advogados. A inclusão de portugueses cujos laços com o Brasil se manifestam a partir de, pelo menos, um dos critérios anteriormente apresentados - apoio, suposto ou real, a D. Pedro e à Constituição de 1826 - permite que se amplie a pesquisa, já que, como esperado, num total de 1.406 processos, com pelo menos 6 mil implicados, a esmagadora maioria é composta por portugueses.

\section{Torres VEDras}

Torres Vedras situa-se a 25 milhas a noroeste de Lisboa. Durante as guerras napoleônicas, por sua posição estratégica em relação à capital portuguesa, foi erguido, na então Vila, um dos maiores sistemas de fortificação do Reino:

As denominadas Linhas de Torres, como conjunto organizado de fortificações de campanha, iniciam-se em Outubro de 1809 e, numa primeira fase de construção, estão operacionais em Outubro de 1810 com 126 fortes. Em 1812, à data da conclusão, o sistema defensivo da cidade de Lisboa, compunha-se por 178 fortificações (não contando com as erigidas na cidade de Lisboa). [...] Prevendo-se uma provável Invasão Francesa após 1811, continuam os trabalhos de melhoramento até 1814, momento em que a artilharia é retirada das posições defensivas. (Noivo, 2010, p. 18)

Os dados sistematizados por João Manuel Rodrigues Pereira sobre a população do Concelho de Torres Vedras informam que, já em 1801, habitavam 
a vila 3.354 moradores, e 15.230 o Termo. ${ }^{8}$ As invasões napoleônicas vieram interromper o acentuado ritmo de crescimento da população do Concelho de Torres Vedras, notório ao longo do século XVIII e retomado a partir da década de $1820 .{ }^{9}$ Os dados para 1826, o ano da outorga da Carta Constitucional por D. Pedro, mostram que o Concelho de Torres Vedras contava com 4.316 fogos: 829 na vila e 3.487 no Termo.

Em 1828, ano da subida de D. Miguel ao trono português, o número total de domicílios apresentou um leve crescimento, passando a 4.543 fogos, e o de habitantes foi estimado em 19.025 , dos quais apenas $21 \%$ residentes na vila, a maioria, portanto, vivendo na área rural. Os dados que localizamos para a população do Distrito de Torres Vedras no Mapa do distrito do Batalhão dos voluntários realistas (Mapa do distrito [...] de Torres Vedras, 1829), separado por Freguesias, aponta para um total de 4.754 fogos e 19.761 moradores, um discreto crescimento que apenas reforça o acerto das estimativas feitas por Pereira (2000).

A atividade econômica que se afirmou nas primeiras décadas do século XIX foi a produção de vinho. Em 1835 registram-se 825 lagares. ${ }^{10}$ Se o número aponta para a desconcentração da propriedade da terra, por outro lado, encobre o fato de que grande parte da produção se concentrava nas maiores propriedades. Apesar de presente, o azeite, produzido em 38 lagares, em 1835, não tem posição relevante. Os bons solos de Torres Vedras ainda permitiam a produção de trigo, milho, fava, legumes e feijão branco, produtos destinados à subsistência da população do Concelho (Pereira, 2000, p. 31).

Ainda que considerada mais ritualística do que de apoio ativo, a adesão da população de Torres Vedras à revolução liberal vintista foi imediata, o que não se verificou em todos os concelhos portugueses. No dia seguinte à recepção do ofício enviado pela Junta do Porto, os camaristas, reunidos no dia 19 de setembro de 1820, fizeram a aclamação ao novo regime, com luminárias e missas cantadas. Procedeu-se à eleição direta e universal dos novos membros da Câmara, passando o número de vereadores de três para nove, como previsto pela legislação para os concelhos maiores. A pronta adesão também se verificou quando do juramento das bases da Constituição Política da Nação Portuguesa, momento em que a Câmara Municipal volta a manifestar a sua adesão ao regime liberal jurando a Carta Constitucional. A primeira experiência liberal, como se sabe, foi efêmera. Já a partir da Vilafrancada, em maio de 1823, as eleições para as Câmaras retornam ao modelo vigente no Antigo Regime, voltando a serem indiretas e ao número de três vereadores (Pereira, 2000, p. 45-47). Desse ano em diante, o recrutamento dos grupos políticos do Con- 
celho, eleitores e elegíveis, passam a obedecer, cada vez mais, a critérios que irão opor realistas e liberais.

As divisões políticas parecem se acentuar com a outorga da constituição por D. Pedro, em 1826. As autoridades e boa parte da população do Concelho acorreram ao juramento da constituição, comemoraram o retorno da Carta, ${ }^{11}$ seguindo o clima de "festa e renovação política" (Cassino, 2015, p. 284) que se verificou na capital do Reino, Lisboa.

Como era de se presumir, sempre tendo em vista o Concelho de Torres Vedras, a partir de 1828, ano do golpe desferido por D. Miguel e que o instala no trono português, cresce o recrutamento de eleitores e representantes, baseado na rejeição e, posteriormente, na exclusão daqueles reputados como liberais, variando dos tidos como duvidosos até os liberais consumados. A partir de então, "o jogo da escolha das vereações está totalmente nas mãos dos realistas” (Pereira, 2000, p. 95). A garantia do sucesso político estava alicerçada em um batalhão de voluntários realistas que chegou a ter entre 500 e 600 praças, comandados por um major reformado. Mesmo na estimativa mais conservadora, as brigadas da contrarrevolução representavam algo em torno de 2,6\% da população concelhia (Pereira, 2000, p. 28). Em agosto de 1831, 24 pessoas se encontravam detidas na vila, a sua maioria sob a acusação de tramar contra D. Miguel. No final daquele mês, foi instaurada uma devassa para apurar o envolvimento dos implicados em atividades "subversivas" contrárias ao rei usurpador, conforme mencionado anteriormente.

\section{Os “inimigos” De D. Miguel}

Instaurada a devassa, a ordem seguinte, dada pelo chefe de polícia da Corte, foi a de que se abrisse processo para cada um dos 14 implicados (ANTT, Maço 55, n. 16). O corregedor de Viana iniciara os trabalhos, mas viu-se impossibilitado de prosseguir com suas tarefas, sendo logo substituído pelo escrivão de Torres Vedras. A mudança teve efeito sobre o andamento das investigações. O chefe de polícia demonstrou sua apreensão de que os inquéritos não fossem encaminhados a contento, o que o levou a orientar o escrivão a que, se não pudesse "proceder aos quatorze sumários... que organizasse a outros tantos". As preocupações do chefe de polícia tinham razão de ser. De fato, apenas a metade dos processos relacionados na devassa (sete) foi instaurada e se encontra no Fundo dos Feitos Findos, no Arquivo Nacional da Torre do Tombo, em Lisboa.

No quadro abaixo, temos a relação dos presos, a ocupação e a acusação que 
recaía sobre os implicados na devassa. Em destaque, negritados, os nomes daqueles cujos processos foram abertos. Percebe-se que a maioria dos réus exercia atividades próprias ao contexto urbano, como a de confeiteiro, de merceeiro, de empregado público, ocupações sobrerrepresentadas, considerando-se o perfil predominantemente rural do Concelho. A acusação consistiu na fórmula "declarar-se inimigo de D. Miguel”, o que poderia significar, muitas vezes, posicionar-se favoravelmente a D. Pedro I do Brasil e, depois, IV de Portugal, como se verá.

\section{Quadro 1 - Envolvidos na devassa aberta em Torres Vedras}

\begin{tabular}{|c|c|c|}
\hline Nome & Ocupação & Acusação \\
\hline $\begin{array}{l}\text { 1. José Faustino Gomes } \\
\text { (Pernambuco) }\end{array}$ & Cirurgião & $\begin{array}{l}\text { Declarar-se inimigo de } \\
\text { D. Miguel }\end{array}$ \\
\hline 2. João Gaspar da Costa e Silva & Procurador de causas & $\begin{array}{l}\text { Declarar-se inimigo de } \\
\text { D. Miguel }\end{array}$ \\
\hline 3. José Eloy da Silva Lobo & Mercador & $\begin{array}{l}\text { Declarar-se inimigo de } \\
\text { D. Miguel }\end{array}$ \\
\hline 4. José Maria Prestes Torres & Não consta & $\begin{array}{l}\text { Declarar-se inimigo de } \\
\text { D. Miguel }\end{array}$ \\
\hline 5. José Pedro Pereira & Merceeiro & $\begin{array}{l}\text { Declarar-se inimigo de } \\
\text { D. Miguel }\end{array}$ \\
\hline 6. Rufino José Garcia & Caixeiro & $\begin{array}{l}\text { Declarar-se inimigo de } \\
\text { D. Miguel }\end{array}$ \\
\hline 7. Antônio Eustáquio & Não consta & $\begin{array}{l}\text { Declarar-se inimigo de } \\
\text { D. Miguel }\end{array}$ \\
\hline 8. Eustáquio José Francisco & Fazendeiro & $\begin{array}{l}\text { Declarar-se inimigo de } \\
\text { D. Miguel }\end{array}$ \\
\hline 9. Felix Simões & Negociante & $\begin{array}{l}\text { Declarar-se inimigo de } \\
\text { D. Miguel }\end{array}$ \\
\hline $\begin{array}{l}\text { 10. Fernando José Cardozo de } \\
\text { Figueiredo }\end{array}$ & $\begin{array}{l}\text { Boticário e escrivão da } \\
\text { Câmara de Ericeira }\end{array}$ & $\begin{array}{l}\text { Declarar-se inimigo de } \\
\text { D. Miguel }\end{array}$ \\
\hline 11. Francisco Sales Ferreira & Confeiteiro & $\begin{array}{l}\text { Declarar-se inimigo de } \\
\text { D. Miguel }\end{array}$ \\
\hline 12. D. Joanna Afra & Não consta & $\begin{array}{l}\text { Declarar-se inimigo de } \\
\text { D. Miguel }\end{array}$ \\
\hline $\begin{array}{l}\text { 13. José Antônio Barreiros de } \\
\text { Magalhaes }\end{array}$ & Escrivão das julgadas & $\begin{array}{l}\text { Declarar-se inimigo de } \\
\text { D. Miguel }\end{array}$ \\
\hline 14. José Damaso de Carvalhosa & $\begin{array}{l}\text { Coronel desligado da } \\
\text { milícia de Torres Vedras }\end{array}$ & $\begin{array}{l}\text { Declarar-se inimigo de } \\
\text { D. Miguel }\end{array}$ \\
\hline
\end{tabular}

Fonte: Processo político (ANTT, Maço 17, n. 7) 
As prisões feitas em Torres Vedras não se limitaram aos implicados na devassa. Foram encontrados na documentação $0^{12}$ outros oito presos contra os quais foram abertos processos, entre os quais o próprio Temudo, conforme o quadro a seguir:

Quadro 2 - Presos processados em

Torres Vedras que não constam da devassa

\begin{tabular}{|c|c|c|}
\hline Nome & Ocupação & Acusação \\
\hline $\begin{array}{l}\text { 1. Bernardos } \\
\text { Antunes }\end{array}$ & Sapateiro & $\begin{array}{l}\text { Por ser constitucionalista e por chamar } \\
\text { "a brejeiro" D. Miguel }\end{array}$ \\
\hline $\begin{array}{l}\text { 2. Diogo Carlos } \\
\text { Temudo de } \\
\text { Mendonça }\end{array}$ & $\begin{array}{l}\text { Desertor do Regimento } \\
\text { de artilharia de Torres } \\
\text { Vedras }\end{array}$ & $\begin{array}{l}\text { Dar vivas aos sediciosos e péssima } \\
\text { conduta moral e política }\end{array}$ \\
\hline $\begin{array}{l}\text { 3. Elias Batista } \\
\text { Ribeiro }\end{array}$ & Caixeiro de mercearia & Uso de termos injuriosos contra D. Miguel \\
\hline 4. Paulo Brunete & Lavrador & $\begin{array}{l}\text { Inimigo do regime absolutista e } \\
\text { encontrado com cartas e papéis sediciosos }\end{array}$ \\
\hline $\begin{array}{l}\text { 5. Clariano José } \\
\text { Machado Rego }\end{array}$ & Não consta & Posse de papéis sediciosos \\
\hline 6. Filipe Neri & Lavrador & $\begin{array}{l}\text { Preso com um grupo de rebeldes } \\
\text { miguelistas, pelo comandante da escolta, } \\
\text { para castigo, visto ter-se retardado na } \\
\text { marcha, vindo depois para a cadeia do } \\
\text { Limoeiro com os mesmos miguelistas }\end{array}$ \\
\hline 7. João Batista & Furriel & $\begin{array}{l}\text { Dizer que seu regimento deveria se juntar } \\
\text { aos rebeldes do Porto em } 1828\end{array}$ \\
\hline $\begin{array}{l}\text { 8. João Eustáquio } \\
\text { Gomes }\end{array}$ & Caixeiro & Espalhar notícias falsas e aterradoras \\
\hline $\begin{array}{l}\text { 9. Felix Francisco } \\
\text { Pereira }\end{array}$ & Cordoeiro & $\begin{array}{l}\text { Inimigo de } \mathrm{D} \text {. Miguel, de péssima conduta } \\
\text { e falto de religião }\end{array}$ \\
\hline $\begin{array}{l}\text { 10. Joaquim } \\
\text { Marcelino Salustiano } \\
\text { da Silva }\end{array}$ & $\begin{array}{l}\text { Contador e } \\
\text { distribuidor do Juízo } \\
\text { de Torres Vedras } \\
\end{array}$ & Partidário do regime liberal \\
\hline $\begin{array}{l}\text { 11. José Manuel dos } \\
\text { Reis }\end{array}$ & $\begin{array}{l}\text { Escrivão dos exercícios } \\
\text { dos Julgados }\end{array}$ & Espalhar notícias falsas e aterradoras \\
\hline $\begin{array}{l}\text { 12. Manuel Joaquim } \\
\text { de Campos }\end{array}$ & Alfaiate & $\begin{array}{l}\text { Por não possuir passaporte e proferir } \\
\text { expressões sediciosas em uma taverna da vila }\end{array}$ \\
\hline 13. Manuel Faustino & Carvoeiro & $\begin{array}{l}\text { Proferir expressões sediciosas e ofensivas } \\
\text { à religião e a D. Miguel }\end{array}$ \\
\hline
\end{tabular}

Fonte: Lima, 1972. 
A leitura de cada processo em separado não permite que se estabeleçam relações de proximidade entre os implicados que pudessem sugerir uma trama concertada em Torres Vedras. A exceção dá-se apenas no caso do preso Eustáquio José Francisco e de D. Joana Afra, que eram irmãos. No processo de Eustáquio (ANTT, Maço 17, n. 7), dona Joana é acusada pelas testemunhas de ter infamado o nome do Rei ao afirmar que, além de "pequeno e brejeiro", D. Miguel era "lacaio matador de machos". Retornaremos, logo adiante, às acusações que recaíam sobre o seu irmão. Afora isso, em nenhum momento, as palavras dos acusados são confrontadas com as proferidas por qualquer outro implicado que aparece na devassa. O que não quer dizer que não pudessem se conhecer, apesar das dimensões do Concelho, um dos maiores de Portugal.

Dos processos localizados, optou-se - a partir dos critérios apresentados na introdução: as ligações dos implicados com o Brasil e a adesão a D. Pedro I - por abordar três personagens, dos quais apenas um deles, o confeiteiro Francisco Sales Ferreira, aparece na devassa.

\section{“Do BRASIl A SALVAÇÃO, EU ESPERO A TODA HORA"}

A loja do confeiteiro Francisco Sales Ferreira foi um importante local de sociabilidade política de Torres Vedras (ANTT, Maço 28, n. 12). Não por outro motivo, era referida por frequentadores e pelos moradores da Vila como "Câmara Baixa", uma alusão à casa legislativa das monarquias liberais que reunia os representantes dos comuns, em oposição aos nobres. Naquele local, eram "admitidos barbeiros, alfaiates e outros aonde lhes lia a gazeta fazendo uma análise sobre os mesmos objetos”, de acordo com o depoimento de uma testemunha, o Padre José Correia de Oliveira. A acusação foi confirmada por uma depoente, referida apenas pelo primeiro nome, Bárbara, de acordo com quem "Sua loja foi intitulada Câmara Baixa em consequência das reuniões que na mesma se fazia". O advogado do réu não desmentiu a acusação de que o seu estabelecimento fosse o centro da recepção das notícias políticas, porém alegou que tal se limitou aos períodos em que o liberalismo fora exitoso:

Nunca em tempo algum na loja dele se fizeram reuniões falando contra o atual governo, e só sim, no tempo das cortes de 1820 era um dos assinantes dos Diários e por esse motivo à sua loja iam algumas pessoas lê-los e ouvi-los ler, mas logo que essas foram dissolvidas deixou o respondente de ser assinante e nunca mais na sua loja se tornaram a ler os diários. (ANTT, Maço 28, n. 12) 
Houve quem atestasse que as tais reuniões prosseguiram, mesmo no reinado de D. Miguel e, se fosse verdade, ocorriam às escondidas, já que, após a sua subida ao Trono, instalara-se a perseguição a qualquer tipo de encontro dessa natureza, sendo passível de denúncia da parte de milicianos a serviço do rei. Algo mais grave, porém, poderia ter acontecido, tendo como palco a confeitaria quando eclodiu a revolução do Porto, em $1828 .{ }^{13}$ Ali se estariam recrutando, ainda de acordo com a mulher de nome Bárbara, voluntários para lutar com os revoltosos aliciados por Francisco Sales.

Francisco Sales Ferreira tinha 52 anos quando foi preso na cadeia de Torres Vedras. Era um homem de posses, um "comerciante rico" e com "muitos meios de subsistência", de acordo com o testemunho de vários moradores. Além da confeitaria, era proprietário de algumas fazendas, herdadas de sua esposa. Ocupou cargos públicos, como o de tesoureiro dos novos direitos, o de feitor e louvador das derramas das sisas - taxação cujos recursos eram utilizados na manutenção dos expostos da Vila - e de cobrador das décimas (1828), essa última função exercida por nomeação dos vereadores da Vila, sendo, por fim, tesoureiro da Casa Real da Décima da Comarca. Certamente por se tratar de cargos relacionados à cobrança de tributos, serviram à argumentação de seu advogado de que foram tais "perigosas incumbências" que o tinham indisposto com vários moradores a ponto de testemunharem contra ele e faltarem com a verdade em seus depoimentos.

Apesar de ter pertencido à Irmandade de Nossa Senhora da Conceição, ereta na Igreja de São Pedro e, dessa forma, concorrer para as festividades religiosas, e também as cívicas, da comunidade, o mesmo Padre José Correia de Oliveira atestava que Francisco Sales falava mal "da religião incitando contra os ministros do Altar dizendo que era gente inútil”. As críticas seriam tão recorrentes que chegaram a afastar alguns potenciais clientes, como no caso do beneficiado Bento Mateus Duran, que "deixou de frequentar a mesma loja por ouvir coisas contra a religião", fato suficiente para que o prelado concluísse que "sempre foi, e ainda o é, um refinado constitucional, e por consequência, inimigo do Altar e do Trono".

Não faltaram imputações ao suspeito de atitudes que povoavam o imaginário popular, que mobilizava cores, ${ }^{14}$ hinos, símbolos. Desse modo, em uma ocasião, "o mesmo sumariado pegou em uma boneca que representava a constituição e se pôs a bailar com ela em cima do balcão", de acordo com o trabalhador José Matias.

O costume de simbolizar a constituição com uma boneca teria se iniciado em Portugal por volta de 1823. A inspiração viera da Espanha, onde esses ri- 
tuais simbólicos ocorriam em "cerimónias burlescas que acompanhavam o derrube da lápide constitucional, a primeira preocupação dos 'facciosos', logo que ocupavam uma povoação". ${ }^{15}$ Ocasionalmente, aparecem nas fontes referências a liberais portando suas bonecas representando a constituição. É o caso de Domingos Nunes, sapateiro, natural de Tomar, e de João Ferreira, criado de servir, natural de Coimbra, ambos acusados, entre outros "crimes", de andar pelas ruas de Lisboa saudando a entrada da Esquadra francesa no Tejo, em 1831, cantando e a "andarem com uma boneca, que afirmavam ser a Constituião que os havia de governar" (ANTT, Maço 15, n. 13). Porém, o fato de os registros provirem das testemunhas de acusação e a consulta à historiografia mostrar que se tratava, invariavelmente, de manifestações de realistas, enxovalhando o símbolo, ${ }^{16}$ põe em dúvida as informações de que os referidos liberais teriam, de fato, usado os objetos de forma tão ostensiva, na hipótese, improvável, de o possuírem. As tais bonecas figuraram ainda em poemas da lavra dos ultrarrealistas, como o que se segue: "A menina já morreu/ Foi-se enterrar à maré/ Disseram os peixes todos/ Isto, que diabo é?” (Vasconcelos, 1982, p. 18).

Infelizmente, nem sempre a sentença proferida consta do processo ou é suficientemente esclarecedora para sermos informados sobre quais depoimentos das testemunhas foram aceitos pelas autoridades. No caso de Francisco Sales, muitas das suspeitas referiam-se ao fato de ele ter manifestado grande júbilo quando da outorga da constituição ao país, por D. Pedro I, em 1826. Teria dito, até mesmo, de acordo com o lavrador Manoel Miranda, que "não gostava da primeira constituição, mas esta [a de 1826] é que é fixa, e nunca há de acabar". O mesmo lavrador relatou que, ouvindo as salvas pela morte de D. João VI, em Torres Vedras, o confeiteiro e proprietário Francisco Sales, em conversa com um morador do lugar, afirmou que, vago o trono, quem deveria governar era "a senhora imperatriz rainha", mas afirmou que ela não podia, por ser estrangeira. Ao que o outro respondeu que, então, deveria ser D. Miguel, ao que o confeiteiro redarguiu "O senhor D. Miguel... [é] suspeito" e quem havia de governar era D. Pedro e "quando não a constituição por quem dava até a última pinga de sangue".

Com o retorno da ordem constitucional em Torres Vedras, Francisco Sales, "personagem que mais se identifica com uma maior convicção liberal" (Pereira, 2000, p. 101), foi eleito vereador da Câmara Municipal da Vila para o biênio 1834-1836.

Um aspecto que se destaca do material apreendido pelas forças policiais aos acusados de se opor a D. Miguel é a recorrência com que são encontrados 
versos e trovas, sejam de próprio punho, seja de autoria de terceiros. A José Dâmaso da Costa Carvalhosa e Silva, coronel desligado da milícia e proprietário em Torres Vedras, por exemplo, foram apreendidos uns versinhos em que se afirmava que "D. Miguel não era filho de D. João VI". Como não há menção a D. Pedro ou ao Brasil no processo que sofrera, a passagem da história de vida do miliciano será abordada apenas em outra oportunidade (ANTT, Maço 15, n. 7).

Já entre os papéis de Paulo Brunete, fazendeiro de 60 anos e morador do lugar de Bandalhoeira, foram encontrados, além de um impresso dando notícia "da saída de D. Pedro do Império do Brasil”, cinco quadras "à constituição" e um soneto sobre Napoleão. Infelizmente, aparece apenas a menção aos poemas e não os originais, transcritos ou recolhidos a Brunete.

A mesma testemunha que dissera que Brunete apregoava, em sua casa, que "até os gatos são constitucionais" e que, se não fossem, "os matava", o Padre Francisco Pedro de Oliveira, cura da Freguesia de São Pedro dos Grilhões, do lugar da Azueira, afirmou ter ouvido notícias sobre os dois filhos do fazendeiro, afirmando que ambos haviam se juntado aos liberais do Porto. Um deles, Francisco, ainda se achava, àquela altura, reunido aos rebeldes, enquanto o outro, que tinha o mesmo nome do pai, Paulo, "foi depois para o Rio de Janeiro". Em seu interrogatório, perguntado se "não era verdade o ter dois filhos com os rebeldes e haver-lhes escrito que se deixassem de seguir o Partido Constitucional os havia de deserdar, nunca mais os tornaria a tratar por filhos nem mais lhe cruzavam a porta”, o réu se limitou a dizer que seu filho Paulo se encontrava "na América", no Rio de Janeiro, onde ocupava uma cadeira de matemática. Do segundo filho, dissera, só tinha a notícia de que se encontrava na Inglaterra.

Temos mais informações de que o Rio de Janeiro era o destino de outros perseguidos pelo regime de D. Miguel no processo movido contra Clariano José Machado Rego (ANTT, Maço 13, n. 11). Em uma carta, cujo remetente não nos é dado a conhecer, lê-se que "O médico cansado com essa maroteira embarcou ontem no paquete para Inglaterra e de lá para a França para de lá se transportar ao Rio". ${ }^{17}$ A maroteira, certamente uma referência aos corcundas, aos apoiadores de D. Miguel, traduzia-se na perseguição aos seus opositores, como ao próprio Clariano, que se encontrava homiziado em um quintal "no lugar da Ribeira de Maria Afonso, Julgado da Rebaldeira”, quando foi preso, em 10 de fevereiro de 1829. Clariano tinha, então, 62 anos.

Entre os seus papéis apreendidos pela polícia, também foram encontradas cartas trocadas com liberais, seus conhecidos, que seguiram para a Inglaterra 
com o objetivo de passar ao Brasil; jornais com notícias sobre a conjuntura internacional da Europa, nas décadas de 1820 e 1830, além do escrito de D. Pedro aos portugueses cujo introito é: "Duas mil léguas de distância que me acho de vós". Chama mais atenção, porém, a grande quantidade de versos de próprio punho, escritos pelo réu em louvor a D. Pedro I e à Constituição. No conjunto, apenas dois poemas fogem ao tema principal, sendo escritos em tom trocista e licencioso. Ainda que encontremos sonetos, prevaleceram as trovas ou quadras.

O escrivão deixou registrado que foram encontrados com Clariano "papéis com quadras". A leitura dos versos mostra que se aproximam mais estritamente da trova, na qual cada conjunto de quatro versos tem sentido completo, revelando o seu poder de síntese. Apesar de Clariano não parecer dos mais hábeis em métrica, da sua pena saíram versos em redondilha ou setissílabos, com rimas no estilo simples, em que apenas o segundo e o último versos rimam entre si. ${ }^{18}$

A poesia em trova, como é sabido, situa-se em uma zona transicional entre as linguagens oral e escrita. Discussões de gênero poético à parte, os versos de Clariano cumpriam o papel designado ao formato, na medida em que poderiam permitir, pela singeleza, uma conexão com o público, uma comunicação mais direta. O fazendeiro de Torres Vedras, preso exatamente sob a acusação de portar "papéis sediciosos, cartas, proclamações e versos", tinha a constituição e D. Pedro I como o leitmotiv de sua criação poética: Preferir a morte à vida/ Fugindo à escravidão/ É caráter dos que adoram/ Liberal constituição; Teu Trono excelso ó Pedro/ Tem por base o coração/ Dos portugueses que adoram/ Liberal constituição. Nos versos seguintes, a união entre a Constituição e o primeiro imperador do Brasil deixa clara que a Carta a que se refere é a de 1826, outorgada por D. Pedro a Portugal: Escrita em letras d'oiro/ Com a maior perfeição/ Mandou Pedro aos lusitanos/ Liberal constituição.

O exame da caligrafia, a partir do cotejo com a correspondência ativa de Clariano, também encontrada entre os papéis apreendidos pelos responsáveis por sua prisão, revela que era ele o autor dos versos. Se alguma dúvida restasse sobre a autoria, outro aspecto permite dizer que as trovas eram de sua lavra, como no poema: Mandou Pedro aos lusitanos/ Quanto estava em sua mão/ Uma tei geral uma lei igual para todos/ Liberal constituição. Temos conosco, portanto, o borrador de Clariano, o que permitiria, se fosse o caso, fazer a crítica genética de sua criação poética, não fora para tão grande empreitada tão curto o repertório. Pode-se afirmar, ainda, sobre os versos de Clariano, que sabem mais à militância contra a tirania do que à pretensão artística. ${ }^{19}$ Os ver- 
sos que reproduzimos por último mostram como então remanesciam, entre as pessoas comuns, os vínculos entre as partes do recém-superado Império Luso-Brasileiro, conforme se vem afirmando: Do Brasil a salvação/ Eu espero a toda hora/ Tormentos sofra, emboral Até que chegue a pernissão remissão.

\section{CONSIDERAÇÕES FINAIS}

Serge Gruzinski, em seu artigo "Os mundos misturados da monarquia católica e outras connected histories”, chama atenção para a importância do estudo das trajetórias dos personagens que transitaram pelos quatro continentes, tendo como referência o mundo planetário do sistema imperial da época moderna, inaugurado pelas monarquias católicas, Espanha e Portugal, no século XV (Gruzinski, 2001, p. 175-195).

A partir dos anos 1500, portanto, multiplicaram-se as "mobilidades intercontinentais, os nomadismos"; aumentou progressivamente a "facilidade para deixar um lugar pelo outro", o "poder de se adaptar a âmbitos variados a fim de circular sem obstáculos nos mundos da Monarquia” (Gruzinski, 2001, p. 191).

Na mesma direção, Sanjay Subramanyan assinala que foram esses personagens que tornaram possível a circulação de mercadorias, seja no sentido mais estrito dos "produtos do Novo Mundo - pimenta, batata doce e tabaco, primeiramente, mas também ouro e prata - [que] foram introduzidos até na China e na Índia" (Subrahmanyam, 2017, p. 15), seja no sentido mais amplo, o da circulação de textos e ideias ao longo dos séculos XVI e XVII (Subrahmanyam, 2017, p. 16-17).

A crise de tais arranjos imperiais, que se acelera nas primeiras décadas do século XIX, só fez intensificar o trânsito de pessoas entre os continentes, acrescido agora de um contingente de exilados sociais e políticos, composto não apenas por pessoas provenientes de grupos cosmopolitas, de comerciantes de grosso trato, de autoridades reais, mas também de pessoas simples, algumas delas representadas neste artigo. O avanço da contrarrevolução, corporificada na restauração das monarquias na Europa, que se seguiu à derrota do império napoleônico, em 1815, multiplicou o número de desterrados, de desertores, de degredados, dos quais é exemplo Diogo Carlos Temudo de Mendonça, com o qual iniciamos nossa narrativa. Temudo, que já circulara compulsoriamente entre Torres Vedras, Angola e Brasil, foi mais uma vez condenado ao exílio, desta feita para Guiné Bissau, como se viu, agora sob a acusação de opositor ao regime reacionário de $\mathrm{D}$. Miguel. 
A experiência do exílio marcou profundamente a dinâmica do liberalismo e da contrarrevolução nas primeiras décadas dos anos 1800, fazendo com que os dois movimentos se consubstanciassem, desde a sua emergência, não apenas como fenômenos "transnacionais", mas também transcontinentais. Não à toa, o poeta espanhol Manuel José Quintana y Lorenzo (1772-1857) afirmou que a "luta universal entre revolução e contrarrevolução definia a política do mundo em que viviam e não só a dos respectivos países" ${ }^{20}$ Os exilados dos dois campos políticos, em boa medida, foram os responsáveis por tornar uma causa que, à primeira vista, pareceria "nacional" - em que pese o fato de o termo nacional ser impreciso, justamente, para esse momento em que as nações modernas estavam em construção - em um movimento transcontinental.

Os amigos do fazendeiro Clariano, morador em Torres Vedras, que esperavam, na Inglaterra, o momento oportuno para viajar para o Brasil, enquadram-se nessa categoria. Os filhos de Paulo Brunete, Paulo e Francisco, também. Eles foram forçados a se deslocar, num momento em que o exílio social e político intensificava as movimentações no interior da Europa do sul e entre ela e o continente americano. Ao pai deles, Brunete, obrigado a permanecer em Portugal sob o poder dos ultrarrealistas, num claro exemplo de que "o exílio é de quem fica” (Polito, 1994, p. 14), o recurso à forma poética, por mais simples que fossem os estilos, provavelmente satisfazia a necessidade de superar os limites da linguagem prosaica das cartas e dos discursos. Brunete buscava, talvez, uma forma de manifestação mais universal, que traduzisse o ideal de um liberalismo sem pátria, porque era a pátria de todos. Uma linguagem poética adaptada ao conteúdo de demandas contra o despotismo e pela liberdade.

\section{Processos políticos CONSUltados}

ANTT - Arquivo Nacional da Torre do Tombo. Processo crime movido contra Diogo Carlos Temudo de Mendonça, desertor do Regimento de Artilharia n. 1, natural de Torres Vedras. ANTT, Maço 14, n. 4.

ANTT - Arquivo Nacional da Torre do Tombo. Processo crime movido contra João Eustáquio Gomes, caixeiro. ANTT, Maço 37, n. 10.

ANTT - Arquivo Nacional da Torre do Tombo. Processo crime movido contra José Faustino Gomes, cirurgião, natural de Pernambuco, Brasil, filho de Brás António da Silveira Gomes e de Felícia Francisca de Jesus, casado com Maria Violante de Carvalho Gomes, preso em Torres Vedras 
por ser um exaltado partidário do regime liberal. Pelos mesmos motivos estavam também presos na cadeia da referida vila José Pedro Pereira, merceeiro, Francisco de Sales Ferreira, confeiteiro, José António Barreiros de Magalhães, escrivão das Julgadas, João Gaspar da Costa e Silva, procurador de causas, José Elói da Silva Lobo, mercador, Rufino José Garcia, José Dâmaso da Costa Carvalhosa e Silva, coronel desligado do Regimento de Milícias, todos de Torres Vedras, Fernando José Cardoso de Figueiredo, boticário e escrivão da Câmara de Ericeira, Félix Simões, negociante na Ericeira, D. Joana Afra, José Maria Prestes Torres, Eustáquio José e António Eustáquio do Turcifal. ANTT, Maço 55, n. 16.

ANTT - Arquivo Nacional da Torre do Tombo. Aviso da Intendência geral de polícia da Corte ao Juiz de Fora de Torres Vedras, de 13 de agosto de 1831. In: ANTT, Maço 55, n. 16.

ANTT - Arquivo Nacional da Torre do Tombo. Processo crime movido contra Eustáquio José Francisco, fazendeiro, natural do Turcifal, filho de Eustáquio da Silva e de Catarina Franco, preso juntamente com Francisco de Sales Ferreira, confeiteiro, José Pedro Pereira, merceeiro, José António Barreiros de Magalhães, escrivão das Julgadas, João Gaspar e Silva, procurador de causas, José Elói da Silva Lobo, mercador, Rufino José Garcia, José Dâmaso de Carvalhosa, coronel desligado de Milícias, todos de Torres Vedras, Fernando José Cardoso de Figueiredo, boticário e escrivão da Câmara de Ericeira, Félix Simões, negociante na mesma vila, D. Joana Afra, José Faustino Gomes, cirurgião, José Maria Prestes Torres, e António Eustáquio, todos de Turcifal, em virtude da devassa aberta em Torres Vedras com o fim de se saber quais as pessoas partidárias do regime liberal, em virtude do pronunciamento de se declarar inimigo de D. Miguel e proferir frases ofensivas à sua dignidade. Por Acórdão de 3 de Agosto de 1832 foi condenado a degredo de seis meses para Óbidos e a 10.000 réis para as despesas da Relação. ANTT, Maço 17, n. 7.

ANTT - Arquivo Nacional da Torre do Tombo. Processo crime movido contra Francisco de Sales Ferreira, confeiteiro de Torres Vedras e daí natural. ANTT, Maço 28, n. 12

ANTT - Arquivo Nacional da Torre do Tombo. Processo crime movido contra Domingos Nunes, sapateiro, natural de S. Pedro do Rego, Tomar, filho de José de Freitas e de Mariana Antónia, casado com Maria Joaquina das Mercês; João Ferreira, criado de servir, natural de Sobral Grande, 
Coimbra, filho de José Ferreira e de Maria da Costa; e João Duarte Videira, tendeiro, natural de Póvoa Pegas, Coimbra, filho de Joaquim da Conceição e de Maria da Conceição. ANTT, Maço 15, n. 13.

ANTT - Arquivo Nacional da Torre do Tombo. Sumário contra Clariano José Machado Rego, natural de Alenquer. ANTT, Maço 13, n. 11.

\section{REFERÊNCIAS}

ALEXANDRE, Valentim. Os sentidos do império: questão nacional e questão colonial na crise do Antigo Regime português. Porto: Afrontamento, 1993.

BRAGA, Paulo Drumond. Os pobres dos meninos de Palhavã: esmolas para as gentes de Lisboa. Lusíada. História, Lisboa, n. 9, 2013.

BRANCATO, Braz Augusto Aquino. Don Pedro I de Brasil, possible rey de España: una conspiración liberal. Porto Alegre: Edipuc-RS, 2014.

BURKE, Peter. Cultura popular na Idade Moderna: 1500-1800. São Paulo: Companhia das Letras, 2009.

CANAL, Jordi. Guerras de cores: aproximações à história da contrarrevolução em Espanha e Portugal. In: FERREIRA, Maria de Fátima Sá e Melo (org.). Contrarrevolução, espírito público e opinião no sul da Europa (sécs. XVIII e XIX). Lisboa: Centro de Estudos de História Contemporânea Portuguesa, 2009. p. 49-71.

CARDOSO, António Monteiro. A revolução liberal em Trás-os-Montes (1820-1834): Povo e as elites. Porto: Afrontamento, 2007.

CASSINO, Carmine. Portugal e a Itália: emigração, Nação e memória (1800-1832). 2015. Tese (Doutorado em História Contemporânea) - Faculdade de Letras, Universidade de Lisboa, Lisboa, 2015.

FARIA, Fabio Alexandre. Circulações Internacionais e Liberalismo: o exílio liberal português, 1828-1832. 2015. Dissertação (Mestrado em História Moderna e Contemporânea) - Instituto Universitário de Lisboa, Lisboa, 2015.

GONÇALVES, Andréa Lisly. Aspectos da história e da historiografia sobre o Brasil e Portugal das primeiras décadas do Século XIX. História da Historiografia, Mariana, v. 10, p. 32-55, 2012.

GONÇALVES, Andréa Lisly. Cidadãos teóricos de uma nação imprecisa: a ação política de estrangeiros no reinado de D. Miguel, 1828-1834. Tempo, Niterói, v. 21, p. 171191, 2015.

GONÇALVES, Andréa Lisly. Liberalismo e irreligião no reinado de D. Miguel: o caso do pernambucano José Faustino Gomes (Portugal, 1828-1834). Topoi, Rio de Janeiro, v. 20, n. 41, p. 368-393, 2019. 
GRUZINSKI, Serge. Os mundos misturados da monarquia católica e outras connected histories. Topoi, Rio de Janeiro, p. 175-195, 2001.

LIMA, Jorge Hugo Pires de. Processos políticos do reinado de D. Miguel. Coimbra: Biblioteca Geral, 1972. p. 717.

MACHADO, André Roberto de Arruda. Redesenhando caminhos: o papel dos representantes do Grão-Pará na primeira legislatura do Império do Brasil (1826 -1829). Almanack Braziliense, São Paulo, n. 10, p. 75-97, 2009.

MENZ, Maximiliano Mac. As "geometrias" do tráfico: o comércio metropolitano e o tráfico de escravos em Angola (1796-1807). Revista de História, São Paulo, n. 166, p. 185-222, p. 190, 2012.

MENZ, Maximiliano Mac; ACIOLI, Gustavo. Resgate e mercadorias: uma análise comparada do tráfico luso-brasileiro de escravos em Angola e na Costa da Mina (século XVIII). Afro-Ásia, Salvador, n. 37, p. 43-73, 2008.

MOURÃO, Fernando Augusto Albuquerque. A evolução de Luanda: aspectos socio-demográficos em relação à Independência do Brasil e ao fim do tráfico. In: PANTOJA, Selma; SARAIVA, José Flávio Sombra. Angola e Brasil nas rotas do Atlântico. Rio de Janeiro: Bertrand Brasil, 1999.

NOIVO, Marco António do Carmo Gomes. A $1^{a}$ e a $2^{a}$ linhas de Torres: a valorização do património e o turismo cultural. 2010. Dissertação (Mestrado em Arte, Património e Teoria do Restauro) - Faculdade de Letras, Universidade de Lisboa, 2010.

ORMSBY, James Wilmot. An account of the operations of the British army and of the state and sentiments of the people of Portugal and Spain. London: Printed for James Carpenter, 1809.

PAQUETTE, Gabriel. The Brazilian Origins of the 1826 Portuguese Constitution. European History Quarterly, Thousand Oaks, p. 444-471, 2011.

PEREIRA, João Manuel Rodrigues. Elites locais e liberalismo: Torres Vedras, 17921878. Torres Vedras: Linhas de Torres, 2000.

PEREIRA, Mirian Halpern. Do Estado liberal ao Estado Providência: um século em Portugal. São Paulo: Edusc, 2012.

POLITO, Ronald. Minas: o dentro no dentro. In: MORAES, Frederico; POLITO, Ronald. Fani Bracher. Rio de Janeiro: Salamandra, 1994. p. 14.

RODRIGUES, Jaime. "Neste tráfico não há lugar reservado": traficantes portugueses no comércio de africanos para o Brasil entre 1818 e 1828. História, São Paulo, v. 36, 2017.

SALGADO, Graça. Fiscais e meirinhos: a administração do Brasil colonial. Rio de Janeiro: Nova Fronteira, 1985.

SILVA, Ana Cristina Nogueira da. Tradição e reforma na organização político-administrativa do espaço, Portugal, finais do século XVIII. In: JANCSÓ, Istvan (org.). Brasil: formação do Estado e da Nação. São Paulo: Hucitec: Unijuí: Fapesp, 2003. p. 297-318. 
SILVA, Luiz Gustavo Martins da. Entre penas e impressos: Aspectos da experiência política de exilados liberais no Brasil contra o regime de D. Miguel (1826-1837). 2019. Dissertação (Mestrado em História) - Instituto de Ciências Humanas e Sociais, Universidade Federal de Ouro Preto, Mariana, 2019.

SIMAL, Juan Luis. Exilio y liberalismo internacional, 1814-1833. Una propuesta de interpretación. Madri. Seminario de investigación. Departamento de Historia Contemporánea. Universidade Complutense de Madri (UCM). 29 de marzo, 2011. UAM.

SIMAL, Juan Luis. Emigrados: España y el exilio internacional, 1814-1834. Madrid: Centro de Estudios Políticos y Constitucionales, 2012.

SOUSA, Maria Leonor Machado de. Torres Vedras vista pelos militares britânicos na Guerra Peninsular. Comemoração bicentenário, 1810-2010, Linhas de Torres Vedras, Torres Vedras, 2009:2010.

SUANZES-CARPEGNA, Joaquim Varela. O constitucionalismo espanhol e português durante a primeira metade do século XIX (um estudo comparativo). História Constitucional, n. 11, p. 237-274, 2010. Disponível em: http://historiaconstitucional. com.

SUBRAHMANYAM, Sanjay. Em busca das origens da História Global: aula inaugural proferida no Collège de France, em 28 de novembro de 2013. Estudos Históricos, Rio de Janeiro, v. 30, n. 60, p. 219-24, 2017.

VASCONCELOS, Maria Emília de. Miguelismo no Alto-Minho. Cadernos Vianenses, Viana do Castelo, t. 12, p. 18, 1982.

\section{NOTAS}

${ }^{1}$ Bolsista de produtividade do CNPq e do Programa Pesquisador Mineiro (Fapemig). A pesquisa contou com uma bolsa de Pós-doutorado Sênior do CNPq realizado sob a supervisão da Profa. Dra. Gladys Sabina Ribeiro.

${ }^{2}$ https://geneall.net/fr/forum/157700/diogo-carlos-de-mendonca/ Os meninos de Palhavã eram os filhos bastardos de D. João V, D. Antônio, D. Gaspar e D. José, que foram legitimados pelo pai em 1742. Ficaram assim conhecidos porque foram instalados, pelo pai, na Quinta de Palhavã, anteriormente propriedade da Condessa de Sarzedas (Braga, 2013).

${ }^{3}$ Sobre as províncias do Norte no pós-Independência, ver: Machado, 2009.

4 "Zonas periféricas do antigo sistema luso-brasileiro, todas elas ofereciam resistência à recolonização, aos novos circuitos mercantis que o reino português desejava impor, em detrimento dos interesses e das forças já enraizadas" (Alexandre, 1993, p. 107).

${ }^{5}$ Peter Burke utiliza, no seu estudo da Europa Moderna, a categoria povo comum para designar o "conjunto da não elite, incluindo mulheres, crianças, pastores, marinheiros, mendigos e os demais grupos sociais". Optou-se, neste trabalho, pelas designações pessoas co- 
muns; gente comum, porque elas permitem que se identifique um grupo dos setores populares, proveniente do antigo terceiro Estado, que partilha características semelhantes sem, contudo, desconhecer-lhe certa heterogeneidade (Burke, 2009, p. 11).

${ }^{6}$ Os quadrilheiros seriam agentes de polícia responsáveis pela segurança pública urbana em cada concelho de Portugal e sua origem remonta à Idade Média, tendo subsistido até o início do século XIX. Tinham como missão principal prender os transgressores e entregá-los às autoridades judiciais.

${ }^{7}$ Em 15 de agosto de 1828, o governo de D. Miguel instituiu, na Casa de Suplicação, uma "Comissão para julgar todos os crimes cometidos contra a Real Pessoa de El Rei... contra a Segurança do Estado”. Essa comissão era composta por um juiz relator e por nove juízes adjuntos.

${ }^{8}$ Nessa data, o Concelho de Torres Vedras era composto por 20 freguesias, quatro da vila e 16 do Termo (Pereira, 2000, p. 29). Sobre a organização política, administrativa e eclesiástica em Portugal, no final dos anos 1700, ver: Silva, 2003, p. 297-318.

${ }^{9}$ A composição do Concelho havia sofrido leve alteração contando com 19 freguesias.

10 "O predomínio da vinha tornara-se esmagador em toda a extensão compreendida entre Torres Vedras, Alenquer, Merceana, Corujeira, S. Domingos de Carmões, Sobral de Monte Agraço, Ribaldeira, Runa e Dois Portos” (Pereira, 2000, p. 33). Lisboa era o principal mercado dos vinhos produzidos em Torres Vedras.

${ }^{11}$ Para uma análise da outorga da Constituição a Portugal por D. Pedro em 1826, ver: Paquette, 2011.

${ }^{12}$ Optamos por manter o nome de Filipe Neri na relação dos presos apenas por se tratar de Torres Vedras. O seu processo faz parte de um total de 28 documentos que compóem o catálogo dos processados políticos do reinado de D. Miguel, mas que, na verdade, se refere a prisões feitas quando da vitória das forças liberais, uma vez tendo a guerra civil sido decidida em favor de D. Pedro.

${ }^{13}$ A revolução liberal do Porto teve início a 16 de maio de 1828 . Contrária à entronização de D. Miguel, seu objetivo era restabelecer a ordem jurídica constitucional a partir da Carta de 1826. Sobre o movimento, ver, entre outros: Gonçalves, 2019.

${ }^{14}$ Os miguelistas “identificavam-se com o 'vermelho' ou 'encarnado', já que se tratava da cor da casa real de Bragança” (Canal, 2009). Já os liberais adotaram o azul e o branco e, de acordo com algumas interpretações, o teriam feito por serem as cores da Maçonaria (Faria, 2015, p. 16).

${ }^{15}$ Em Braga, conduziram uma boneca num esquife pelas ruas, entoando um ofício de defuntos, no fim do qual gritavam: "Quem quiser dizer missa por alma da menina, vá dizella nas cloacas da sé” (Cardoso, 2007, p. 193).

16 "Mais um cortejo houve ainda neste período, este contra a Constituição de 1826, classificado de 'índole sarcástica'. Em que a dita Constituição, crismada de 'Menina' e representada por um manequim com grosseiras roupas de mulher, é passeado pela urbe, entre 
apupos e pauladas que a vão desfazendo, no seu carro, e por fim queimada com o resto dos trapos que a compunham, 'a afrontar todos os pedreiros livres' que ainda a defendessem". (Vasconcelos, 1982, p. 18).

${ }^{17}$ Sobre o exílio liberal no Brasil, sobretudo o de portugueses, durante o reinado de D. Miguel, ver: Silva, 2019.

${ }^{18}$ As outras formas de rima são: a paralela, na qual o primeiro verso rima com o último e o segundo com o terceiro, a tradicional, na qual o primeiro verso rima com o terceiro e o segundo com o último, e a emparelhada, em que o primeiro verso rima com o segundo e o terceiro com o quarto. Agradeço a Solange Ribeiro de Oliveira e a Sérgio Alcides pelas pormenorizadas explicações sobre a arte de versejar, o que me permitirá voltar ao tema em trabalhos futuros.

${ }^{19}$ Há outro poema, da lavra de Clariano, em oito versos, que consta dos autos, que não tem a política como inspiração e é escrito de forma picaresca: Eu jamais pude gostar/ Doutra súcia que não seja/ Petisco, vinho, cerveja/E disto muito chupar/ Também gosto de rir, zombar/ Tendo à destra o canjirão/ Para aplaudir a fumação/ Quatro tragos bebendo/ Ir dois versos fazendo/ Sem estro, nem medição.

${ }^{20}$ Tradução minha para: "la lucha universal entre revolución y contrarrevolución definia la política del mundo en el que vivian y non solo la de sus países respectivos” (Simal, 2011, p. 1).

Artigo recebido em 26 de dezembro de 2019.

Aprovado em 22 de abril de 2020. 